\title{
Analysing and visualizing spatio-temporal landslide patterns
}

\author{
Daniel Hölbling ${ }^{\mathrm{a},}$ *, Raphael Spiekermann ${ }^{\mathrm{b}}$, Andrea Binn ${ }^{\mathrm{c}}$, Harley Betts ${ }^{\mathrm{b}}$ \\ ${ }^{a}$ Department of Geoinformatics - Z_GIS, University of Salzburg, Schillerstrasse 30, 5020 Salzburg, Austria, \\ daniel.hoelbling@sbg.ac.at \\ ${ }^{b}$ Landcare Research, Private Bag 11052, Manawatu Mail Centre, Palmerston North 4442, New Zealand, \\ SpiekermannR@landcareresearch.co.nz,BettsH@landcareresearch.co.nz \\ ${ }^{c}$ Department of Geodesy and Geoinformation, Vienna University of Technology, Schallergasse 25/13, 1120 Vienna, Austria, \\ binnandrea@gmail.com \\ * Corresponding author
}

\begin{abstract}
Landslide erosion is a serious land management problem in many parts of the world. In New Zealand, a combination of steep erodible hill country, frequent and intense rainstorms, and recent forest clearance for pastoral farming has led to extensive landslide erosion in many parts of the country. Effective mitigation measures against landslide erosion and its consequences require a detailed understanding of the history, location, extent, and severity of landsliding. Consequently, the preparation and availability of comprehensive and meaningful landslide inventories and spatial representation using advanced cartographic techniques can support mitigation of landslide erosion, risk communication, decision making and land management.
\end{abstract}

Remote sensing and new geospatial technologies have significantly increased objectivity and efficiency of geomorphological mapping, while at the same time recent developments in GIScience allow different theoretical perspectives on space, time, processes, and systems to be merged (Bishop et al., 2012; Napieralski et al., 2013). The complexity of natural phenomena such as landslides requires advanced and innovative image analysis methods for adequate and effective landslide inventory mapping (Guzzetti et al., 2012). Remote sensing data is well suited for detecting landslides and for deriving spatio-temporal landslide patterns. Manually or semi-automatically mapped landslides from optical satellite images or aerial photographs can be used as input for creating landslide pattern or hotspot maps, which constitute an easy-to-grasp visual representation of the worst landslide-affected areas following landslide triggering events such as heavy rainstorms.

For analysing and visualizing spatio-temporal landslide patterns we use historical and recent aerial photography from five different dates, ranging from 1944 to 2011, for a study site near the town of Pahiatua, New Zealand. Landslide hotspots are identified from the distribution of semi-automatically detected landslides using object-based image analysis (OBIA) (cf. Hölbling et al., 2016). The development of semi-automated image classification techniques such as OBIA offers the potential to considerably improve existing manual landslide mapping techniques, in particular the time needed for landslide detection can be significantly reduced while achieving acceptable mapping accuracies. The semi-automatically identified landslide polygons are rasterized at $1 \mathrm{~m}$ cell size and aggregated to $25 \mathrm{~m}$ pixel resolution by calculating the sum of $1 \mathrm{~m}$ landslide pixels per $25 \mathrm{~m}$ cell. The resulting map is a landslide cover or density map which displays the proportion of landslide area covering each pixel $\left(625 \mathrm{~m}^{2}\right)$ in percent. Figure 1 shows an example of the identified landslide hotspots based on the OBIA mapping using the aerial photograph from 2005. The comparison of the landslide hotspots based on the OBIA mapping with those based on manually mapped landslides shows very similar results for all periods. 

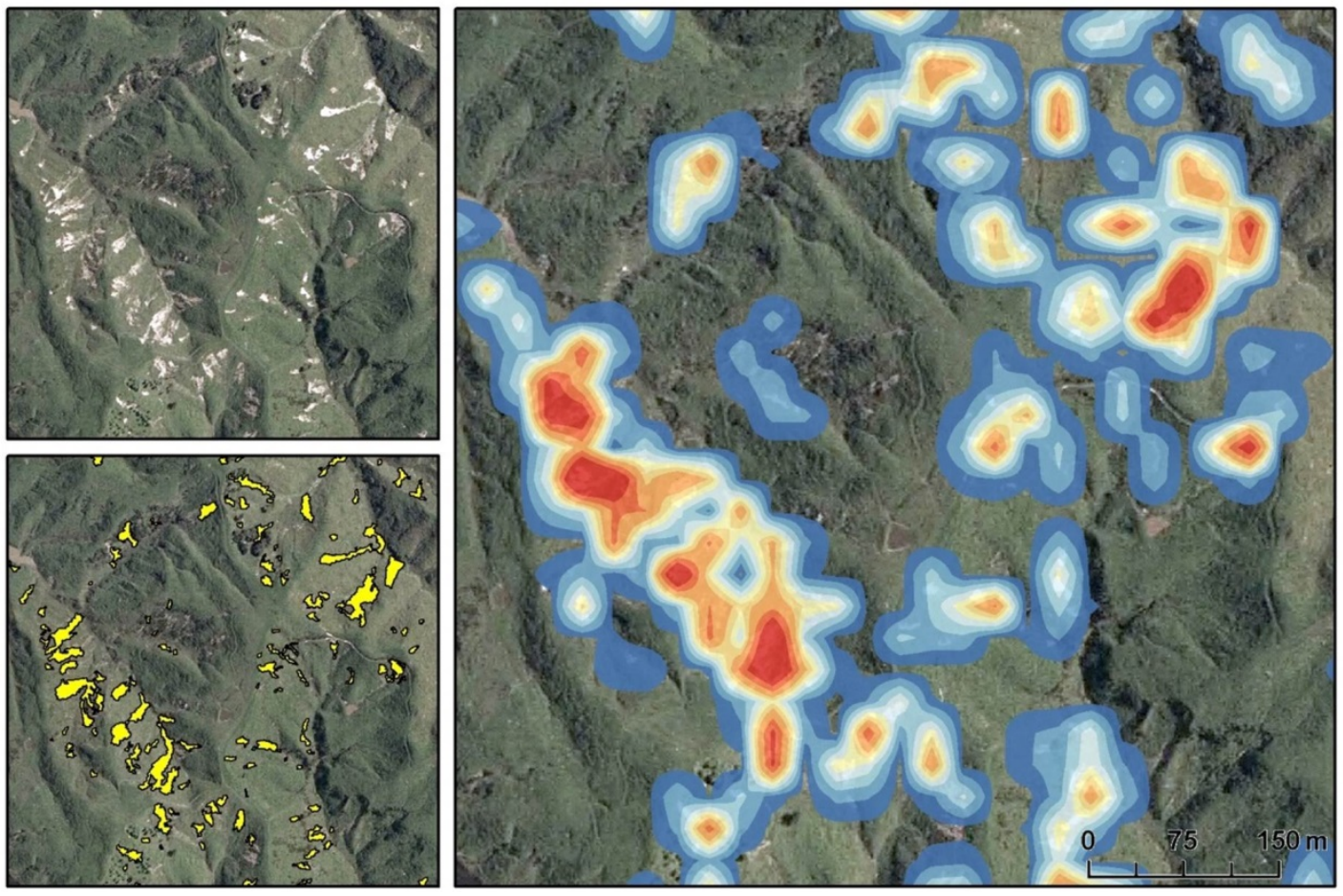

Landslide cover

[\% of 25 m pixel]

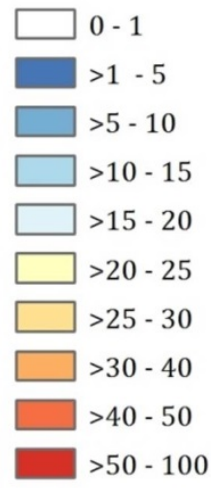

Figure 1. Aerial photography from 2005 showing numerous landslides on a subset of the study area (upper left), landslide polygons mapped with OBIA (in yellow; lower left), and landslide hotspots calculated based on the OBIA mapping showing the proportion of landslide area covering each pixel $\left(625 \mathrm{~m}^{2}\right)$ in percent. A bilinear interpolation is used to create a smoother representation of the result.

Advanced visualization techniques and cartographic representations are finally used to illustrate the evolution of the landslide hotspots over space and time. Such a space-time and multidimensional representation of landslide patterns can reveal relevant new information about past and recent landslide activity and can be valuable for risk communication and targeted mitigation of landslide erosion.

Keywords: Landslides, Remote Sensing, Spatio-temporal Patterns, Hotspots, OBIA

\section{Acknowledgements}

This research has been supported by the Austrian Science Fund through the project MORPH (Mapping, Monitoring and Modelling the Spatio-Temporal Dynamics of Land Surface Morphology; FWF-P29461-N29) and by the New Zealand Ministry of Business, Innovation and Employment through the project STEC (Cost-effective targeting of erosion control to protect soil and water values; contract no. 1819-38-010 J).

\section{References}

Bishop, M.P., Allan James, L., Shroder, J.F. and Walsh, S.J. (2012). Geospatial technologies and digital geomorphological mapping: Concepts, issues and research. Geomorphology, 137, 5-26.

Guzzetti, F., Mondini, A.C., Cardinali, M., Fiorucci, F., Santangelo, M. and Chang, K.-T. (2012). Landslide inventory maps: New tools for an old problem. Earth-Science Reviews, 112, 42-66.

Hölbling, D., Betts, H., Spiekermann, R. and Phillips, C. (2016). Identifying Spatio-Temporal Landslide Hotspots on North Island, New Zealand, by Analyzing Historical and Recent Aerial Photography. Geosciences, 6, 48.

Napieralski, J.A., Barr, I.D., Kamp, U. and Kervyn, M. (2013). Remote sensing and GIScience in geomorphological mapping. In: Shroder, J.F., Bishop, M.P. (eds.), Treatise on Geomorphology: Remote Sensing and GIScience in Geomorphology, Academic Press, San Diego, CA, 187-227. 